J. Perinat. Med. $12(1984) 193$

\title{
The neonatal significance of selected perinatal events among infants of low birthweight - III. Follow-up studies
}

\author{
R.P.Perkins
}

Division of Maternal-Fetal Medicine,

Department of Obstetrics and Gynecology, University of New Mexico,

School of Medicine, Albuquerque, USA

In prior reports, the early neonatal implications of selected perinatal events among infants of low birth weight were reviewed $[1,2]$. Factors potentially having an influence upon neonatal mortality were surveyed, utilizing an entire three-year experience of babies weighing less than $2001 \mathrm{gm}$ at birth in a large university teaching hospital. It was found that, as expected, birthweight and gestational age had a major impact upon neonatal survival; but maternal hypertension, as well as prolonged ruptured membranes with babies weighing less than $1200 \mathrm{gm}$ or with gestational ages less than 30 weeks had a salutary effect upon the likelihood of survival. Babies of very low birthweight born after premature labor or with isoimmunization were disadvantaged when compared to the population as a whole. The effect of compounding of neonatal complications upon survival was investigated, and it was found that babies experiencing a host of adverse events were more likely to fail to survive than those with relatively uncomplicated courses, when considered by birthweight and gestational age.

Survivors weighing less than $1500 \mathrm{gm}$ at birth from this study period (July, 1973 - June, 1976) were entered into the long-term follow-up study program existing for many years within the University of Colorado Neonatal Division. Results of these investigations upon survivors persisting in the system from 6 to over 30 months are the subject of this report.

\section{Materials and methods}

The original study involved $330^{\circ}$ mothers, cared for at Colorado General Hospital, who delivered 356 live-born infants weighing less than $2001 \mathrm{gm}$. The records on one additional mother and 5 babies could not be made available for review. The birthweight distribution, including survivals through the period of the original study, is listed in Tab. I.

The follow-up program enrolled only babies weighing less than $1500 \mathrm{gm}$ at birth. Tab. II lists survivors weighing 500-1500 gm available for the project. Excluded from these studies were 8 postneonatal deaths, as well as those with anomalies, congenital chronic infections, chromosomal abnormalities, and 17 babies who were lost to ultimate contact by the system, but who were alive and well by reports from elsewhere.

Of those originally weighing $500-900 \mathrm{gm}, 5$ survivors were available for assessment. This

Tab. I. Survivors of original study period

\begin{tabular}{lrlrl}
\hline & \multicolumn{2}{l}{ Born } & \multicolumn{2}{l}{ Survived } \\
\cline { 2 - 5 } Weight (gm) & No. & $\begin{array}{l}\% \\
\text { total births }\end{array}$ & No. & $\begin{array}{l}\% \\
\text { birthweight }\end{array}$ \\
\hline $501-900$ & 47 & 13.3 & 12 & 26.1 \\
$901-1200$ & 47 & 15.9 & 42 & 73.7 \\
$1201-1500$ & 74 & 20.7 & 62 & 84.9 \\
$1505-2000$ & 180 & 50.2 & 170 & 94.4 \\
\hline
\end{tabular}


Tab. II. Survivors weighing 500-1500 gm in follow-up studies

\begin{tabular}{rrll}
\hline Weight (gm) & No. & (\% born) & (\% first report [1]) \\
\hline $500-900$ & 5 & $(10.6)$ & $(41.7)$ \\
$901-1200$ & 31 & $(54.5)$ & $(73.8)$ \\
$1201-1500$ & 42 & $(56.8)$ & $(67.7)$
\end{tabular}

Excludes 8 post-neonatal deaths; anomalies; congenital infections (chronic); karyopathies; those lost to follow-up. Total survivors $=108$. Reviewed here $=78$.

Distribution of neurologic abnormalities by type and magnitude.

\begin{tabular}{rlllll}
\hline Weight (gm) & $\begin{array}{l}\text { Mental } \\
\text { Abnor- } \\
\text { mality }\end{array}$ & $\begin{array}{l}\text { Motor } \\
\text { Abnor- } \\
\text { mality }\end{array}$ & Overall* (\% normal) \\
\hline $500-900$ & $3 / 5$ & $4 / 5$ & $1-3-1-5$ & $(20)$ \\
$901-1200$ & $6 / 29$ & $16 / 30$ & $14-6-11-31$ & $(45)$ \\
$1201-1500$ & $8 / 41$ & $16 / 42$ & $23-10-9-42$ & $(55)$
\end{tabular}

Not all babies could be assessed by all testing parameters.

* Normal-mild deficit-moderate or severe deficit-total.

represented $10.6 \%$ of the original live-born group, and $41.7 \%$ of those covered in our initial reports $[1,2]$. Of those $901-1200 \mathrm{gm}, 31(54.4 \%$ of those born and $73.8 \%$ of those previously reported) were studied. In the weight group 1201-1500 gm, 42 babies were assessed, representing $56.8 \%$ of those born and $67.7 \%$ of those initially reported. In all, there were 108 survivors of the original group of 181 children in these birthweight cate- gories, of whom 78 long-term outcomes are reported.

Tab. II also reviews the frequencies and distribution of severity of detected neurologic deficits in the population followed, utilizing liberal criteria for abnormality.

Children were assessed by the Denver Developmental Screening Test [3] and/or BAYLEY scales [4] for mental and motor handicap. For purposes of analysis, babies were scored as normal (including those judged only borderline abnormal and expected to resolve) and abnormal (from moderate to severe). In addition, an overall score was given to summarize their status, based upon a subjective impression of their degree of handicap. This score ranged from 0 (normal) to 3 (severely affected). These three scoring systems were separately subjected to simple correlations with 44 maternal-fetal factors (see Tab. III) and 26 neonatal categories (see Tab. IV) in all three categories by continuity: corrected chi-square analysis of FISHER's Exact Test using the Statistical Analysis System. Any perinatal event found to show a potential correlation, with a null hypothesis probability of 0.20 or less, was added to the data base for further analysis, in order to determine those factors having the most substantial controlling influence upon outcome. All factors in any two of the three birthweight categories achieving this qualification for analysis were included in the third, even if a lesser

Tab. III. Variables examined for association with handicap

\section{Maternal-Fetal}

\begin{tabular}{lll}
\hline Maternal age & Breech & Abruptio \\
-Race & HBP - 1st TM & Fetal transfusion \\
Parity & HBP - 2nd TM & LFT abnormal \\
Prior preg. (\#) & HBP - 3rd TM & Labor induction \\
Prior abortions (\#) & HBP - labor & Duration, ruptured membranes \\
Family history HBP & HBP - postpartum & GA by dates \\
Personal history HBP & L/S ratio & GA by exam \\
Spontaneous rupture of & Uric acid & APGAR 1 minute \\
membranes & Creatinine clearance & APGAR 5 minutes \\
Bleeding & Cesarean delivery & Gender \\
Fever & Fetal distress & Labor tolerance \\
Rh sensitized & Rapid delivery & Delivery mode \\
HBP on admission & Infection & Alcohol (labor suppression) \\
Referred & Previa & Apresoline \\
\hline
\end{tabular}

HBP = high blood pressure; $\quad \mathrm{TM}=$ trimester $;$

LFT = liver function tests;

$\mathbf{G A}=$ gestational age; \# = number. 
Tab. IV. Variables examined for association with subsequent handicap

\begin{tabular}{lll}
\hline & \multicolumn{1}{c}{ Neonatal } \\
\hline Resp. distress & ? sepsis & (Exchange transfusion) \\
Hyaline membrane disease & Anemia & Hospital stay \\
Hyperbilirubinemia & Apnea/bradycardia & (Thrombocytopenia) \\
Hypocalcemia & Seizures & SGA by dates \\
Hypotension & (Pulmonary hemorrhage) & SGA by exam \\
Hyponatremia & Air leaks & R Index \\
Hypoglycemia & Disseminated intravascular coagulation & M Index \\
Late Acidosis & Intracranial hemorrhage & \\
Patent ductus arteriosus & Anomaly & \\
\hline
\end{tabular}

$(\quad)=$ numbers too small for meaningful analysis; SGA $=$ small for gestational age $(\leqslant 10$ th percentile); $R$ Index $=$ Respiratory Index (see [1]); M Index = Morbidity Index (see [1]).

Tab. V. Variables selected for subsequent analysis

\begin{tabular}{ll}
\hline & Motor deficit \\
\hline $\begin{array}{l}\text { Spontaneous reptured } \\
\text { membranes }\end{array}$ & (APGAR 1) \\
Referred (*) & APGAR 5 \\
Breech & Resp. distress (*) \\
Abruptio (*) & Hypocalcemia \\
Maternal age & Hyponatremia \\
Race & Hypoglycemia \\
HBP on admission & Patent ductus \\
(-) Family history HBP & arteriosus \\
(-) HBP - 3rd TM & Apnea/bradycardia \\
(-) HBP - PP (*) & Hypotension \\
Parity & Anemia \\
GA by dates & Necrotizing \\
Rapid delivery (*) & enterocolitis \\
Meconium (*) & (Anomaly) \\
(Labor intolerance) & (M Index) \\
\hline
\end{tabular}

Variables in parentheses added for interest; significant in other categories

$(-)=$ removed for inadequate numbers

$(*)=$ statistically significant by $x^{2}$; at " $p$ " less than 0.05 . HBP $=$ high blood pressure; $T M=$ trimester; $P P=$ post partum; $\mathbf{G A}=$ gestational age; $R / O=$ rule out.

degree of impact was found in the other birthweight category. The categories selected for .stepwise discriminant analysis are included in Tabs. V-VII.

\section{Results}

Tabs. VIII and IX list antepartal and neonatal factors selected as having a potentially significant influence (either beneficial or detrimental) upon long-term outcome in two or more outcome categories. Factors indicated by the $(+)$ appeared
Tab. VI. Variables selected for subsequent analysis

\begin{tabular}{ll}
\hline & Mental deficit \\
\hline Maternal age & Resp. distress \\
Race & Hyaline membrane \\
Spontaneous ruptured & disease \\
$\quad$ membranes & Hypocalcemia \\
GA by dates & Hypotension \\
Labor intolerance & Patent ductus \\
Meconium & arteriosus (*) \\
Family history HBP & Anomaly \\
(Abruptio) & R Index \\
(Parity) & M Index \\
(Rapid Delivery) & (Hypoglycemia) \\
APGAR 1 & R/O sepsis \\
(APGAR 5) & Thrombocytopenia
\end{tabular}

$(*)=$ statistically significant $($ at $<0.05) ;(-)=$ removed for inadequate numbers; ()$=$ added for interest; significant in other categories.

to have had a beneficial effect upon outcome, in that their occurrence was associated with a markedly lower incidence of subsequent abnormality than their absence. In the case of spontaneous rupture of membranes and motor abnormality, the effect appeared to be non-linear, in that ruptured membranes appeared advantageous to the very lowest birthweight category, and possibly somewhat disadvantageous in the higher weight category.

Tab. $X$ displays those variables ascertained by stepwise discriminant analysis from the factors in Tabs. V-VII to have had the most prodigious association with outcome. In the case of motor deficits, the presence of meconium and a rapid vaginal delivery were found to have the most 
Tab. VII. Variables selected for subsequent analysis

Total score

\section{Parity (*)}

Abruptio

Rapid delivery (*)

Labor intolerance

Meconium (*)

(Spontaneous ruptured membranes)

(Maternal age)

(Race)

(GA by dates)

(-) HBP - 3rd TM

(-) HBP - PP

$(\quad)=$ added for interest; significant in other categories; $(-)=$ removed for inadequate numbers; $(*)=$ statistically significant (at 0.05).

significant association, and $63.3 \%$ of all outcomes could be explained utilizing these two variables alone. None of the many other variables achieved statistical relevance $(F$ to enter $=4.00$ ) when the variables cited were removed.
(-) HBP - labor

(-) Creatinine clearance

Hypocalcemia

Hypoglycemia

Patent ductus arteriosus

Seizures

Anomaly

Resp. distress

M Index (*)

SGA by exam

Hypotension

$\mathrm{R} / \mathrm{O}$ sepsis

Mental abnormalities were found curiously to correlate inversely with the demonstration of hypocalcemia on one or more determinations. Patients with demonstrated hypocalcemia had a markedly reduced incidence of mental handicap as opposed to those without. Birthweight as a continuous variable was found to have a rather linear inverse association with mental handicap, those of higher birthweights having progressively lower incidences of mental handicaps than those in the very lowest birthweight category. Combining these two considerations, $79.5 \%$ of outcomes could be correctly predicted.

When the overall subjective score was reviewed for associations with perinatal events, the presence of meconium was found to be a significant finding. By stepwise discriminant methodology, labor intolerance (as manifested by electronic fetal monitoring signs of fetal distress), when combined with meconium staining, predicted $78.5 \%$ of out: comes $(p=0.017)$. Curiously, labor intolerance was associated with a lower incidence of handicap.

Tab. VIII. Antepartum factors seeming to be of important in two or more areas

\begin{tabular}{lll}
\hline Mental & Motor & Score \\
\hline Meconium & Meconium & Meconium \\
Advanced maternal age & Advanced maternal age & Chicano race \\
Chicano race & Spontaneous ruptured membranes (?) & \\
Spontaneous ruptured membranes (+) & GA by dates (+) & Labor intolerance \\
GA by dates & Abruptio (+) & Abruptio (+) \\
Labor intolerance & Rapid delivery (*) & Rapid delivery \\
& Advanced parity & Advanced parity \\
\hline
\end{tabular}

$(+)=$ seems to confer advantage; $(*)=$ disadvantage statistically significant; $(?)=$ non-linear effect by birthweight.

Tab. IX. Neonatal factors seeming to be of importance in two or more areas

\begin{tabular}{lll}
\hline Mental & Motor & Score \\
\hline Resp. distress & Resp. distress & Resp. distress \\
Hypocalcemia (+) & Hypocalcemia (+) & Hypocalcemia (+) \\
Patent ductus arteriosus (+) & Patent ductus arteriosus (+) & Patent ductus arteriosus (+) \\
Hypotension & Hypotension & Hypotension \\
M Index & & M Index \\
Anomaly & & Anomaly \\
R/O sepsis (+) & & R/O sepsis (+) \\
& & Hypoglycemia
\end{tabular}

$(+)=$ seems to confer some advantage; in the case of patent ductus, advantage is nullified if ligation required. 
Tab. X. Variables found most likely to explain deficit - with \% explained (stepwise discriminant analysis)

\begin{tabular}{|c|c|c|c|c|c|}
\hline Deficit & Variable & $\begin{array}{l}\mathrm{F} \\
\text { to enter* }\end{array}$ & $\begin{array}{l}\text { \% abnormal } \\
\text { without } \\
\text { parameter }\end{array}$ & $\begin{array}{l}\text { \% abnormal } \\
\text { with } \\
\text { parameter }\end{array}$ & $\begin{array}{l}\% \text { explained } \\
\text { with variables } \\
\text { combined }\end{array}$ \\
\hline Motor & $\begin{array}{l}\text { Meconium } \\
\text { Rapid delivery }\end{array}$ & $\begin{array}{r}13.985 \\
6.157\end{array}$ & $\begin{array}{l}33 / 76=43.4 \\
31 / 73=42.5\end{array}$ & $\begin{array}{l}5 / 6=100 \\
7 / 8=87.5\end{array}$ & 63.3 \\
\hline Mental & $\begin{array}{l}\text { Hypocalcemia } \\
\text { Birthweight (continuous variable) }\end{array}$ & $\begin{array}{l}6.781 \\
8.222\end{array}$ & $13 / 41=31.7$ & $5 / 38=13.2$ & \\
\hline Score & $\begin{array}{l}\text { Labor intolerance } \\
\text { Meconium }\end{array}$ & $\begin{array}{r}4.403 \\
13.699\end{array}$ & $\begin{array}{l}11 / 39=28.2 \\
13 / 55=23.6\end{array}$ & $\begin{aligned} 4 / 21 & =19.0 \\
4 / 5 & =80\end{aligned}$ & $\begin{array}{l}78.5 \\
(p=0.017)\end{array}$ \\
\hline
\end{tabular}

* shown in order of selection by the analysis system.

\section{Comment}

If one takes cognizance of the fact that all babies studied weighed less than $1500 \mathrm{gm}$ at birth, the presence of meconium staining may be interpreted as a highly unusual finding. Its presence also suggests the possible influence of growthretarded babies of more advanced gestational age than birthweight would indicate. If one refers to Tab. IV, however, it becomes readily apparent that the factor of small-for-gestational-age (lowest 10th percentile of birthweight for gestational age) was included as a variable, and did not emerge as a statistically significant category. Meconium staining was noted in 12 instances, with a $58 \%$ mortality and an $80 \%$ neurologic morbidity rate among survivors. Only $6 / 12$ babies with this finding were SGA.

Rapid or precipitate delivery, (defined for this study as an unexpectedly brief late first and second stage of labor) has long been suspected of increasing the risk of trauma to the brain of the small premature baby. It is likely that this may explain its association with motor deficits. Likewise, the presence of meconium suggests the possibility of hypoxic brain injury, occurring either de novo or superimposed upon a fragile brain state predating labor. The association between labor intolerance (fetal distress) and a lower incidence of handicap may have resulted from a more aggressive interventionist policy in babies at recognized risk. This question cannot be resolved with certainty in a retrospective study.
The most inscrutable outcome of this very detailed analysis is the apparent "beneficial" effect of hypocalcemia upon subsequent neuorologic function. One can speculate that hypocalcemia, perhaps reflecting more responsive neonatal parathyroid activity, might be a sign of relative health, while its absence might be a manifestation of relative endocrinologic immaturity. It is also possible that hyperventilation and relative alkalosis secondary to aggressive support may have resulted in hypocalcemia through a reduction in the ionized calcium fraction, thereby representing indirect evidence of aggressive ventilatory support. There is no proof for any of the above speculations discoverable by retrospective analysis methods.

A third explanation for all of these outcomes is that one or more of these factors might have achieved statistical significance by chance alone, due to the large number of variables considered. It would be entirely possible that such chance association would be represented here, expect for the rather surprisingly high percentage of outcomes explainable by the very limited number of variables identified. Variables selected by stepwise discriminant analysis for these outcomes readily achieved significance without involving the host of additional factors subjected to analysis. It is therefore felt that these events discovered have a meaningful relationship to the ultimate observations of deficit.

No further attempt will be made in this presentation to speculate upon the significance of the 
variables discovered, nor the lack of significance of the panorama of other variables considered, except to point out that some babies within this very low birthweight category died in the neonatal period. What are reported are the apparent influences of perinatal factors upon deficits among survivors. Factors contributing significantly to demise (perhaps the ultimate deficit) such as birthweight, gestational age, significant respiratory distress, premature labor, abruptio placentae, and other

\section{Summary}

78 babies weighing less than $1500 \mathrm{gm}$ at birth, surviving the neonatal period and available for follow-up, were studied. Data pertaining to perinatal events previously reported were correlated with neurological outcome over a 6-30 month period of evaluation. Motor abnormalities were found to correlate with the presence of meconium and the occurrence of rapid delivery. Mental handicap

Keywords: Follow-up, neonatal, perinatal, prematurity. factors have been dealt with in prior reports $[1,2]$.

It is concluded that meconium staining, though a comparatively rare event in this birthweight group, is an ominous observation. Rapid delivery may predispose to injury, though mechanisms for this injury are unproven. Hypocalcemia appears associated with a better outcome than its absence, as is fetal distress. The reasons for these findings are unknown. correlated inversely with hypocalcemia and birthweight. Overall score correlated with meconium and inversely with labor intolerance. These events were the only ones of a host of factors discovered by stepwise discriminant analysis among many maternal-fetal and neonatal variables. The importance of these observations is speculative.

\section{Zusammenfassung}

Zur Bedeutung einiger ausgewählter Komplikationen in der Perinatalphase für die spätere Entwicklung von Kindern mit niedrigem Geburtsgewicht. III. Nachuntersuchungen Wir beobachteten in einer Nachuntersuchung 78 Kinder mit einem Geburtsgewicht unter 1500 Gramm, die die Neugeborenenperiode überlebten. Dabei wurden Komplikationen, die in der perinatalen Phase aufgetreten und dokumentiert waren, mit der neurologischen Entwicklung über einen Beobachtungszeitraum von 6-30 Monaten korreliert. Motorische Entwicklungsverzögerungen traten gehäuft nach mekoniumhaltigem Fruchtwasser und einer kurzen Geburtsdauer auf. Eine mentale Beeinträchtigung

war um so ausgeprägter, je niedriger das Geburtsgewicht war. Nach Hypocalcämien trat sie zu unserer Überraschung weniger gehäuft auf. Motorische und mentale Verzögerungen korrelierten positiv mit mekoniumhaltigem Fruchtwasser in der Anamnese und negativ mit der Wehenintoleranz. Es wurden nur einige perinatale Komplikationen aus einer Fülle von Beobachtungen herausgegriffen, die man durch eine schrittweise Diskriminationsanalyse der maternal-fetalen und neonatalen Variablen aufstellen kann. Die Bedeutung dieser Beobachtungen ist rein spekulativ.

Schlüsselwörter: Frühgeburt, Nachuntersuchung, Neonatalperiode, Perinatalphase.

\section{Résumé}

Signification néonatale des données périnatales sélectionnées chez les enfants de faible poids de naissance. III - Etudes de la surveillance

On a étudié 78 enfants pesant moins de $1500 \mathrm{~g}$ à la naissance; ayant survécu à la période néonatale et ayant pu être suivis de près. Les données appartenant aux événements périnataux rapportés antérieurement ont été corrélées avec le devenir neurologique sur une période d'évaluation de 6 à 30 mois. On a trouvé que les anomalies motrices sont corrélées avec la présence de méconium et l'existence d'un accouchement rapide. Les handicaps mentaux sont inversement corrélés avec l'hypocalcémie et le poids de naissance. Le score global est corrélé avec la mauvaise tolérance du travail. Ces éléments sont les seuls parmi une foule de facteurs mis en évidence par une analyse discriminative rigoureuse des nombreuses variables materno-fœtales et néonatales. L'importance de ces observations est spéculative.

Mots-clés: Néonatal, périnatal, prématurité, suivi.

Acknowledgement: The author would like to acknowledge the indispensible contribution of LULA LUBCHENCO, M.D., and her staff at the University of Colorado Health Sciences Center, Denver, CO, for their follow-up data which forms the basis for this report; and for her willingness to allow its publication. 


\section{Bibliography}

[1] PER KINS, R. P.: The neonatal significance of selected perinatal events among infants of low birth weight. I. Overall results. Am. J. Obstet. Gynecol. 139 (1981) 546

[2] PER KINS, R. P.: The neonatal significance of selected perinatal events among infants of low birth weight. II. The influence of reptured membranes. Am. J. Obstet. Gynecol. 142 (1982) 7

[3] FRANKENBURG, W. K., A. D. GOLDSTEIN, B. W. CAMP: The revised Denver Developmental Screening Test: Its accuracy as a screening instrument. J. Pediatr. 79 (1971) 988

[4] BAYLEY, N.: Manual for the Bayley scales on infant development. The Psychological Corporation, New York 1969

Richard P. Perkins, M.D.

Division of Maternal-Fetal Medicine

Department of Obstetrics and Gynecology

University of New Mexico

School of Medicine

Albuquerque, New Mexico 87106

USA 


\section{"}

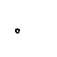

